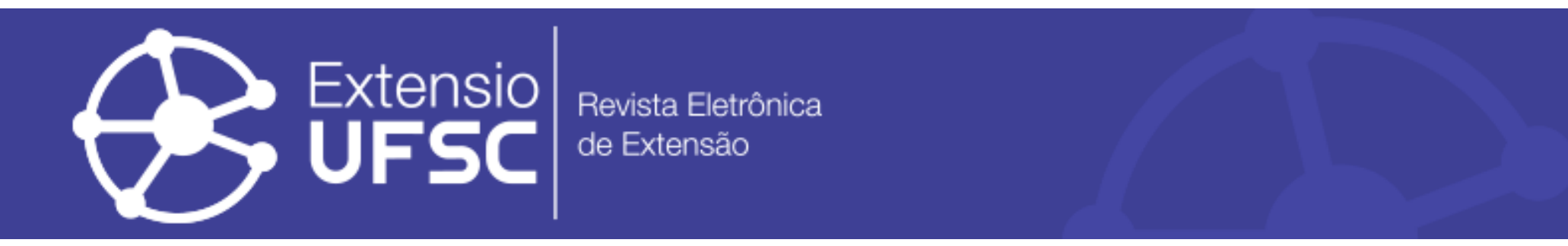

\title{
EDUCAÇÃO PERMANENTE DO PÚBLICO-ALVO PARA DETECÇÃo PRECOCE DE ALTERAÇÕES NEUROMOTORAS INFANTIS
}

\author{
Gustavo Martignago \\ Pontifícia Universidade Católica de Campinas \\ gustavo_martignago93@hotmail.com
}

Maria Valéria Corrêa e Castro Campomori Pontifícia Universidade Católica de Campinas val2003@puc-campinas.edu.br

\begin{abstract}
Resumo
Introdução: O projeto de vigilância do desenvolvimento neuromotor infantil é realizado em um Centro de Saúde de Campinas, SP, no biênio 2016/2017, com destino ao público-alvo: médicos pediatras, enfermeiros, técnicos e auxiliares de enfermagem e agentes comunitários de saúde. Objetivos: Desenvolver sua educação permanente e validar esse resultado com os pais, ou responsável pela criança. Método: oficinas técnicas e socioeducativas com os profissionais envolvidos e utilização da Escala Motora Infantil de Alberta (AIMS) para avaliar crianças com atraso no programa de acompanhamento mensal. Resultados: Produção conjunta de Roteiro para Detecção Precoce de Atraso Neuromotor Infantil pelo públicoalvo. Capacitação e autonomia dos profissionais para identificação de fatores de risco ao desenvolvimento neuromotor infantil e de atraso neuromotor. Conclusão: Estima-se que a educação permanente do público-alvo produza nos pais a conscientização e o conhecimento necessários para acompanhar o desenvolvimento neuromotor de seus filhos e protagonizarem quaisquer alterações que ameacem e comprometam tal desenvolvimento.
\end{abstract}

Palavras chaves: Educação Permanente. Oficinas Socioeducativas. Cartilha Educativa.

\section{PERMANENT EDUCATION OF THE TARGET PUBLIC FOR EARLY DETECTION OF CHILDREN'S NEUROMOTIVE CHANGES}

Abstract

Introduction: The surveillance project of the neuromotor development is carried out in a health centre of Campinas, SP, in the 2016/2017 biennium, with the target audience: pediatricians, nurses, technicians and nursing assistants and community health agents. Objectives: Develop your permanent education and validate this result with the parents, or guardian for the child. Method: educational and technical workshops with the professionals involved and the use of children's Motor Scale Alberta (AIMS) to evaluate children with delay in follow-up. Results: Joint production of roadmap for early detection of Delay by the Child audience Neuromotor. Empowerment and autonomy of professionals to identify risk factors for the development of neuromotor neuromotor delay child. Conclusion: it is estimated that the permanent education of the audience produces the parent's awareness and knowledge needed to accompany the neuromotor development of their children and protagonizarem any changes that threaten and undermine such development.

Key words: Permanent Education. Educational Workshops. Educational Playbook.

\section{EDUCACIÓN PERMANENTE DEL PUBLICO OBJETIVO DE DETECCIÓN PRECOCE DE ENMIENDAS NEUROMOTORAS INFANTILES}

Resumen

Introducción: El proyecto de vigilancia del desarrollo neuromotor se lleva a cabo en un centro de salud de Campinas, SP, en el bienio 2016/2017, con la audiencia: pediatras, enfermeras, técnicos y auxiliares de enfermería y agentes de salud comunitarios. Objetivos: Desarrollar su educación permanente y validar este resultado con los padres o tutores del niño. Método: talleres educativos y técnicos con los profesionales y el uso de niños Motor escala Alberta (objetivos) para evaluar niños con retraso en el seguimiento. Resultados: Producción conjunta de hoja de ruta para la detección temprana del retraso por parte de la audiencia del niño Neuromotor. Empoderamiento y autonomía de los profesionales a identificar factores de riesgo para el desarrollo del niño de retraso neuromotor. Conclusión: se estima que la educación permanente del público produce la conciencia de los padres y los conocimientos necesarios para acompañar el desarrollo neuromotor de los niños y protagonizaren los cambios que amenazan y socavan tal desarrollo.

Palabras clave: Educación Permanente. Talleres Educativos. Guía Educativo. 
Educação permanente do público-alvo para detecção precoce de alterações neuromotoras infantis

\section{INTRODUÇÃO}

As atividades do Plano de Trabalho de Extensão que teve por título Educação permanente do público-alvo para detecção precoce de alterações neuromotoras infantis, das quais deriva o presente estudo, desenvolvidas por uma docente orientadora e um orientando, aluno bolsista da extensão, em uma Unidade Básica de Saúde (UBS) da região metropolitana de Campinas, SP, com a duração de 2016 a 2017, teve por finalidade desenvolver a educação permanente dos profissionais de saúde (público-alvo envolvido) para identificar os fatores de risco e também atraso neuromotor nas crianças de zero a 24 meses de idade, os quais ameaçam a integridade física infantil.

No Manual para Vigilância do Desenvolvimento infantil do Ministério da Saúde (2002), especificamente no contexto da Atenção Integrada às Doenças Prevalentes da infância (AIDPI), encontra-se o termo desenvolvimento neuromotor infantil definido da seguinte maneira:

Aumento da capacidade do indivíduo na realização de funções cada vez mais complexas, e (...) mudanças nas estruturas físicas e neurológicas, cognitivas e comportamentais, que emergem de maneira ordenada e são relativamente duradoras. (OPAS, 2002).

No entanto, para que o desenvolvimento infantil ocorra de forma saudável é importante que haja a interação do ambiente com a tarefa a ser executada e com o indivíduo, sinalizando que os fatores extrínsecos (ambientais) e fatores intrínsecos (biológicos) facilitem a evolução motora da criança, dependendo da maturação do Sistema Nervoso Central (SNC). Portanto, os reflexos motores (estímulo sensorial e resposta motora) são componentes importantes para o decorrer do desenvolvimento infantil, pois se constituem em elementos básicos para o movimento. (FLEHMIG, 2002; CAMPOS E SANTOS, 2005; SPESSATO et. al., 2009; KANG et al, 2017).

Baseando-se na teoria dos sistemas dinâmicos (TSD) definida como o "estudo de sistemas complexos por meio de interação de subsistemas (tais como biológico, cognitivo, social, de percepção e de memória) na produção de comportamento" (BROOKS - SCOTT, 2001), o comportamento motor é produto de vários sistemas, no qual o movimento surge a partir do meio interno, do ambiente e da tarefa. Logo, o SNC deve ser capaz de se adaptar às mudanças ambientais e biomecânicas periféricas. O comportamento da criança para a produção do movimento associa-se às tarefas funcionais ou com os objetivos a serem alcançados pelo indivíduo, para o qual a estratégia motora é definida pelas crianças, pelas 
Educação permanente do público-alvo para detecção precoce de alterações neuromotoras infantis

tarefas e pelo ambiente (BROOKS - SCOT'T, 2001; CAMPOS E SANTOS, 2005; KANG et al, 2017).

Contudo, de maneira resumida, o desenvolvimento neuromotor é caracterizado pela aquisição de habilidades motoras em diversas posturas, e o processo de ganho do desenvolvimento global é composto por: tônus muscular, postura, reflexos primitivos, reações posturais, coordenações sensório-motoras e movimentos espontâneos (MÉLO, 2011; LUCAS et al, 2016). Dessa forma, o crescimento infantil é dividido em quatro trimestres, e neles evidenciam-se a evolução dos padrões de movimentos, onde, o primeiro trimestre é definido principalmente pela postura fetal em flexão, em resposta a uma gama de reflexos e também pelo alinhamento da cabeça. Já no segundo trimestre o crescimento infantil é marcado pelo controle da força da ação da gravidade, além de assumir habilidades de sentar e empurrar. Em relação ao terceiro trimestre a criança adquire a liberdade de movimento, ou seja, explora o ambiente com maior desenvoltura. Finalmente, o quarto trimestre sobressai-se pela deambulação independente (TECKLIN, 2002; CAMPOS E SANTOS, 2005; FONSECA E LIMA, 2008).

Por exemplo, Tecklin (2002) e Shumway-Cook (2010) corroboram que os marcos do desenvolvimento neuromotor incluem o rolar, o arrastar, o sentar, o engatinhar, a conquista da posição ortostática e o deambular independente. Segundo os autores, as crianças adquirem também as habilidades de manipular objetos, correr, subir e apresentar a coordenação óculomanual.

Ainda para Tecklin (2002), a evolução neuromotora infantil relaciona-se com os padrões de movimento que são adquiridos na primeira infância entre o período do nascimento até os seis anos de idade. Contudo, no $12^{\circ}$ mês, onde a criança começa a desenvolver a deambulação, se encerra a aquisição dos padrões de movimento. Sendo assim, do $13^{\circ}$ mês ao $6^{\circ}$ ano de vida ocorre o aprimoramento do desenvolvimento das habilidades motoras adquiridas durante seu primeiro ano. Nota-se que as capacidades motoras que contemplam o período de $13^{\circ}$ a $24^{\circ}$ meses são: correr, agachar e levantar, pular e, consequentemente, a aptidão de pegar objetos acima de sua cabeça e apresentar destreza nos movimentos motores finos, como o uso de suas mãos.

Com base nas ideias descritas anteriormente, o atraso do desenvolvimento neuromotor infantil acarreta um impacto significativo para a saúde da criança, haja vista que altera o curso do desenvolvimento típico e, tem por etiologia fatores de risco e patologias (LUCAS, B. R., 2016; KANG, L., 2017). Para Maia e Williams (2005) “os fatores de riscos são aqueles fatores 
Educação permanente do público-alvo para detecção precoce de alterações neuromotoras infantis

que, se presentes, aumentam a probabilidade de a criança desenvolver uma desordem emocional ou comportamental".

Portanto, os fatores de risco que influenciam as aquisições das habilidades motoras são: os fatores ambientais caracterizados pelas condições sociais, nutrição adequada, educação, uma vez que o entorno do Centro de Saúde envolvido apresenta uma população vulnerável e com problemas socioeconômicos e culturais bastante comprometidos. Destacam-se também os fatores biológicos causados pela prematuridade, doenças pulmonares, como, bronquiolite, pneumonias, entre outras, podendo causar um longo período de hospitalização. (HALPERN, et. al., 2000; SPESATO, et. al., 2009; DORNELAS, et. al., 2015; KANG et al, 2017).

As alterações do desenvolvimento neuromotor podem ocorrer desde o período prénatal em mães cujas condições socioeconômicas e culturais são desfavoráveis, as quais contribuem para que não procurem por acompanhamentos obstétricos preventivos. Já no período perinatal podem ocorrem complicações durante o parto devido à falta de acompanhamento médico, ou também por questões biológicas e genéticas, como por exemplo, sufocamento pelo cordão umbilical, condição esta denominada de "circular de cordão", e tabagismo durante a gestação. No período pós-natal ocorrem doenças infecto contagiosas, como meningites, encefalites, levando, ou não, à hospitalização, muitas vezes complicada e prolongada (AJAREM et al, 2017).

De acordo com o Manual para Vigilância do Desenvolvimento infantil no contexto da Atenção Integrada às Doenças Prevalentes da infância (AIDPI), citado no início desta introdução, reproduz-se abaixo o Quadro 1 com a classificação do desenvolvimento infantil:

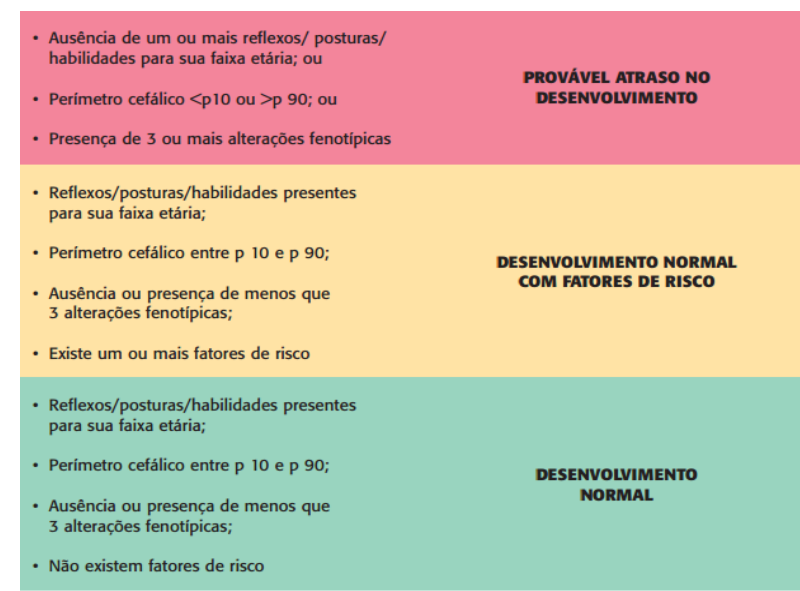

Quadro 1: Classificação do desenvolvimento infantil.

Fonte: Manual para Vigilância do Desenvolvimento infantil no contexto da Atenção Integrada às Doenças Prevalentes da infância (AIDPI), 2002. 
Educação permanente do público-alvo para detecção precoce de alterações neuromotoras infantis

Pela identificação do atraso neuromotor infantil e mesmo dos fatores de risco ao desenvolvimento pelo público-alvo do projeto as crianças tem sido encaminhadas para avaliação, utilizando-se a Escala Motora Infantil de Alberta (AIMS), com o objetivo de confirmar ou não o atraso em questão e proceder ao seguimento da evolução neuromotora até 18 meses e, depois, até os dois anos de idade. A AIMS, sendo uma escala muito utilizada pelos fisioterapeutas na área da neuropediatria, foi desenvolvida por Piper \& Darah (1994), fisioterapeutas canadenses na Província de Alberta, e tem por objetivo avaliar o desenvolvimento neuromotor infantil, como a maturação do sistema nervoso central. As avaliações do desenvolvimento neuromotor são realizadas em bebês ao longo do tempo, de zero a 18 meses de idade. Com isso, a AIMS identifica se os bebês que estão com atraso neuromotor ou se o desenvolvimento prossegue normalmente (TECKLIN, 2002; HERRERO et. al., 2011; MÉLO, 2011). Sendo assim, se identificados com atraso neuromotor, serão encaminhados para tratamentos com profissionais médicos e não médicos, como: neuropediatras, fisioterapeuta, fonoaudiólogo, e terapeuta ocupacional. O detalhamento desta escala motora será tratado em "Método".

Antes de realizar a avaliação por esta escala motora é de extrema importância verificar fatores intrínsecos ou extrínsecos à criança que poderão interferir negativamente nos resultados da avaliação: fome, agitação, irritação e sono são exemplos mais comuns.

É importante a detecção antecipada do atraso do desenvolvimento neuromotor para que ocorra a intervenção precoce, promovendo a neuroplasticidade, que se trata da adaptação dos neurônios do SNC em relação a mudanças das condições ambientais. Essa adaptação ocorre mais fácil e mais rapidamente durante a infância, pois as células do SNC estão em processo de amadurecimento, proporcionando uma capacidade de aprendizagem. Porém, na vida adulta essa capacidade diminui (BORELLA E SACCHELLI, 2008; SOUZA, et. al., 2013). A neuroplasticidade ocorre de diversas maneiras, ou seja, "regenerativa, axônica, dendrítica, somática e habituação, que é uma das suas formas mais simples" (BORELLA E SACCHELLI, 2008; SOUZA, et. al., 2013).

Contudo, durante a estimulação motora são provocados padrões de movimentos funcionais, por influências ambientais e comportamentais, ocorrendo o aprendizado do ato motor, favorecendo a recuperação da função. Para o retorno da funcionalidade, pode ser estimulada a prática de movimentos repetitivos, estimulação sensorial, prática mental e técnicas de auxílio para controle motor (BORELLA E SACCHELLI, 2008; SOUZA, et. al., 2013). 
Educação permanente do público-alvo para detecção precoce de alterações neuromotoras infantis

É importante destacar que a educação permanente dos profissionais de saúde proporcionará o desenvolvimento de sua capacitação e autonomia, explorando suas potencialidades. Assim, o papel do bolsista é contribuir para a educação permanente dos profissionais de saúde da Unidade Básica envolvida e validar os resultados dessa educação pelo acompanhamento direto do público-alvo no momento em que ministram orientações acerca do desenvolvimento neuromotor infantil aos pais, ou responsável pelas crianças.

\section{MÉTODO E MATERIAS}

\section{Oficinas técnicas e socioeducativas}

Trata-se de um plano de trabalho de extensão universitária da Pontifícia Universidade Católica de Campinas (PUC-Campinas) vinculada a Pró Reitoria de Extensão e Assuntos Comunitários da referida Instituição, oficialmente abreviada e citada por PROEXT, em um projeto de Extensão Universitária, cujo título é: Vigilância do desenvolvimento neuromotor infantil em Unidade Básica de Saúde do distrito Noroeste de Campinas, com duração de um biênio (2016/2017), tendo como entidade parceira a Prefeitura Municipal de Campinas. O projeto desenvolve-se em um Centro de Saúde (CS) de nome "Margarida Santos da Silva", no bairro Parque Floresta, no Distrito Noroeste de Campinas - SP. O entorno do CS é caracterizado por bairros carentes constituídos por população de classe média baixa e dependente do Sistema Único de Saúde (SUS).

Foram identificados os profissionais da área da saúde da referida unidade, sendo o público-alvo caracterizado por: 2 enfermeiros, 3 técnicos de enfermagem, 12 auxiliares de enfermagem, 12 agentes comunitários de saúde, e 2 médicos pediatras. Na etapa do início do projeto também foram identificadas 419 crianças de zero a 24 meses de idade, dados estes cedidos pela coordenadora da referida Unidade de Saúde.

\section{Escala Motora Infantil de Alberta (AIMS)}

É um recurso de avaliação observativa com aplicação rápida de aproximadamente 20 a 25 minutos, baixo custo, objetiva, obtenção de valores satisfatórios de validade e confiabilidade, podendo ser realizado um acompanhamento mensal para a detecção precoce de alterações motoras. Porém, é uma escala exclusivamente motora, não possibilitando a detecção de problemas ortopédicos (TECKLIN, 2002; HERRERO et. al., 2011; MÉLO, 2011; SACCANI \& VALENTINI, 2012). 
Educação permanente do público-alvo para detecção precoce de alterações neuromotoras infantis

Foi elaborada contendo 58 itens, organizados em quatro posturas, sendo: 9 itens na posição supina, 21 em prono, 12 na posição sentada e $16 \mathrm{em}$ pé, avaliando o alinhamento postural, os movimentos antigravitacionais e a superfície de contato - sustentação de peso (TECKLIN, 2002; MÉLO, 2011; SACCANI \& VALENTINI, 2012).

A pontuação da AIMS é dada pela observação de cada postura citada anteriormente, e é atribuído um ponto para cada posição observada. Caso um item não seja notado e a criança apresentar uma idade mais avançada, supõe-se que a mesma já realizou aqueles marcos do desenvolvimento, e, então, são computados com um ponto, chamados itens creditados fora da janela motora. Assim que observada a primeira postura realizada pela criança abre-se a janela motora, permanecendo com ela aberta até a última atitude observada; fecha-se, então, a janela, sendo os itens dentro dela creditados, assinalando com o valor de um ponto as posturas observadas, e aos itens não notados concedidos os valores de zero ponto. Depois de realizada a aplicação da escala em sua totalidade será obtida um score, o qual se relacionará à idade da criança avaliada, dando origem ao gráfico de percentil da AIMS da seguinte forma: $5 \mathrm{TH}$ a 10 $\mathrm{TH}$ - indicam atraso no desenvolvimento neuromotor grosso, $25 \mathrm{TH}$ - necessitam de acompanhamento, 50 TH a 90 TH - não necessitam de acompanhamento (PIPER, 1994; TECKLIN, 2002; MÉLO, 2011; SACCANI \& VALENTINI, 2012).

\section{Materiais}

Os materiais necessários para a realização deste plano de trabalho no CS foram fichas de avaliação da escala Motora Infantil de Alberta (AIMS), tatame em EVA ${ }^{\circledR}$ (Etileno Acetato de Vinila) para acomodar as crianças no momento da aplicação da escala motora.

\section{RESULTADOS}

De modo geral, o projeto de extensão foi muito bem aceito pela equipe de profissionais e reconhecidamente ressaltaram a importância da cartilha educativa em linguagem acessível para os pais ou responsáveis das crianças, com o compromisso de a Prefeitura Municipal replicá-la a outras unidades básicas da cidade. Constou da cartilha o ensino, as orientações e as informações acerca dos cuidados básicos em relação às mães e aos filhos para se desenvolverem de maneira saudável, como, por exemplo: incentivo aos pais ou responsáveis quanto às atividades extramuros com bebês e crianças para favorecer a socialização, diminuindo o confinamento no ambiente doméstico; promoção de brincadeiras 
Educação permanente do público-alvo para detecção precoce de alterações neuromotoras infantis

corporais, envolvendo toda a família e outras crianças; orientações quanto às posturas maternas e posições das crianças para o aleitamento materno; instruções das técnicas do aleitamento, promovendo mobilidade areolar, dentre outras, a fim de prevenir o ingurgitamento das mamas, o qual acarretaria o desmame precoce; explicação da importância da hidratação materna durante a manutenção da amamentação, ou galactopoiese; ensino das vantagens e desvantagens da criança permanecer no carrinho, no colo e no solo.

Em decorrência das dificuldades dos profissionais envolvidos para procederem à identificação das alterações do desenvolvimento neuromotor, as oficinas técnicas e socioeducativas promoveram o suporte e conteúdo necessários por meio da elaboração de um roteiro contendo as principais etapas do desenvolvimento neuromotor, separadas por trimestres da vida infantil, até os dois anos de idade. Tal roteiro constituiu o primeiro produto técnico elaborado em conjunto com a equipe de saúde do local e tem-se conhecimento de sua utilização na rotina profissional com as famílias das crianças.

O modelo parcial a seguir exemplifica as figuras referentes à estruturação do roteiro utilizado pelo público-alvo:

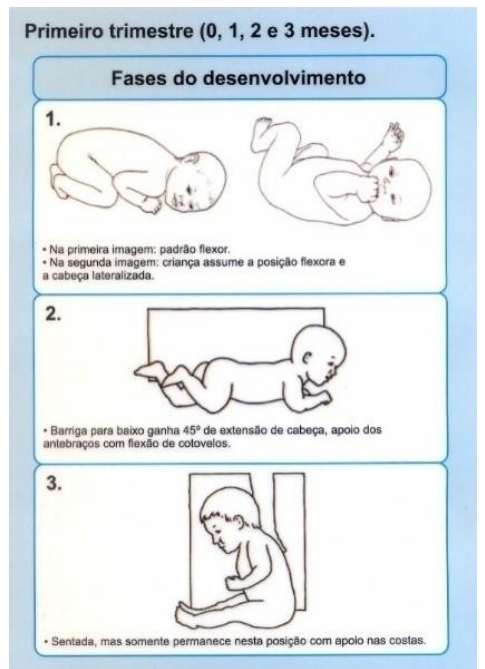

Figura 1: Exemplo de página do roteiro elaborado em conjunto. Fonte: Autoria própria.

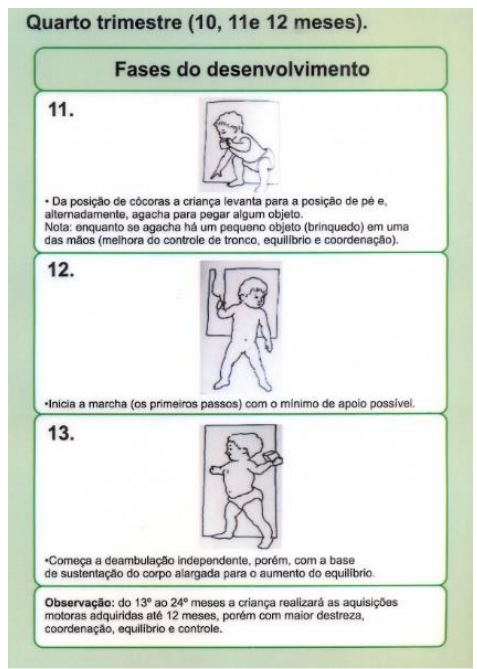

Figura 2: Exemplo outra página do roteiro elaborado em conjunto. 
Educação permanente do público-alvo para detecção precoce de alterações neuromotoras infantis

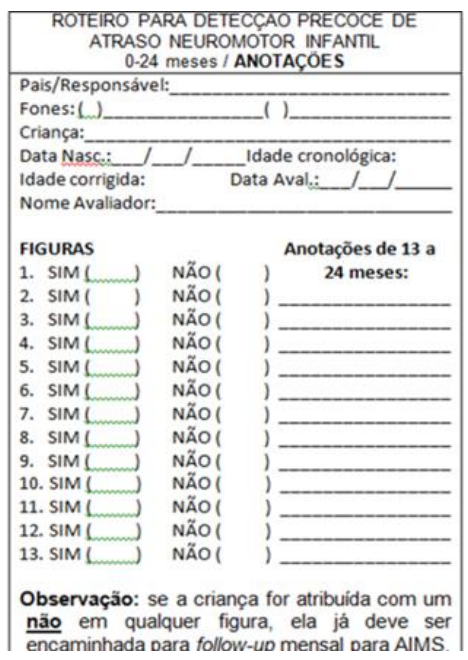

Figura 3: Ficha para registro da avaliação usada pelo públicoalvo. Fonte: Autoria própria.

Para o estudo, foram selecionadas oito crianças, onde uma delas não compareceu em nenhuma das avaliações. Assim, das sete crianças avaliadas, quatro eram prematuras em torno de 30 semanas de gestação, apresentando como fatores de risco longos períodos de hospitalização, bronquiolite viral e "ruptura da membrana espontânea" (Segundo Informações Colhidas da mãe-SIC). Por outro lado, as outras três crianças eram nascidas de parto a termo, apresentando como possíveis fatores desencadeantes para o atraso hospitalizações por intercorrências durante o parto (provável aspiração de mecônio), dificuldade de amamentação e fatores socioeconômico e cultural baixos.

Portanto, sete crianças apresentaram suspeita de atraso neuromotor para aplicação da AIMS. Na sequência, o Quadro 2 demonstra os dados obtidos na AIMS e as características epidemiológicas das crianças identificadas pelo público-alvo do projeto de extensão: 
Educação permanente do público-alvo para detecção precoce de alterações neuromotoras infantis

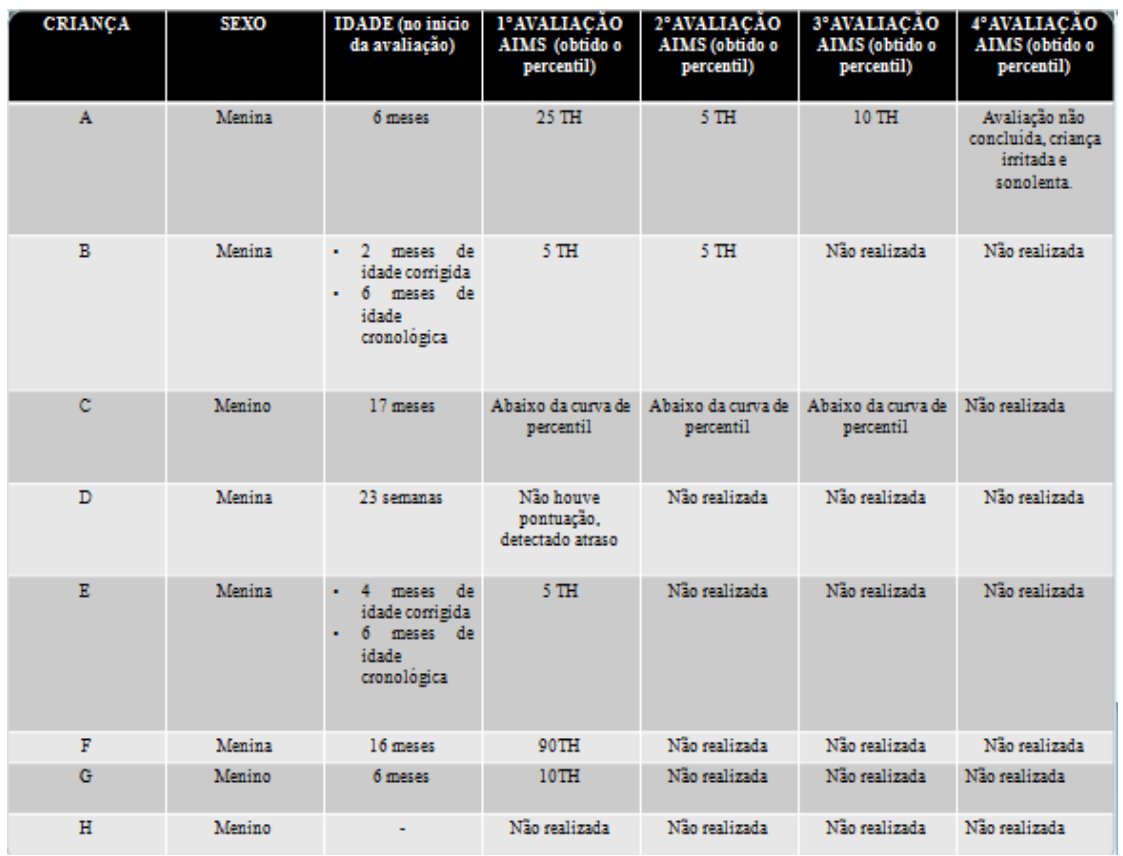

Quadro 2: Características epidemiológicas e resultados das avaliações pela AIMS de crianças identificadas pelo público-alvo.

\section{DISCUSSÃO}

O estudo em questão atentou para o fato de que todas as crianças avaliadas pelo público-alvo precisaram de um acompanhamento mensal, pois os escores obtidos pelo percentil da AIMS mostraram que são necessárias reavaliações periódicas para que se identifique precocemente atraso neuromotor. Com base em tal identificação a população infantil pôde, enfim, ser encaminhada para as áreas médica e fisioterapêutica, a fim de serem incluídas em tratamento ou acompanhamento.

De acordo com o Quadro 2 apresentado nos resultados, podemos apontar que: a criança ' $A$ ' apresentou-se com um desenvolvimento dentro do gráfico de percentil, porém, necessitou de acompanhamento, pois era uma criança com fator de risco cultural e ambiental muito importante (MORAIS et al, 2016; KANG et al, 2017). Já a criança 'B' é um bebê prematuro, necessitou de acompanhamento, pois até o momento detectou-se pequeno atraso com fator de risco biológico e um longo período de várias hospitalizações (SOUZA e MAGALHÃES, 2012). A criança 'C' apresentou um desenvolvimento abaixo da curva de percentil, pois ainda não adquiriu a habilidade de deambulação independente, mas anda com apoio. Sobretudo, esta criança praticamente não foi amamentada e apresentava quedas constantes, sendo necessária a vigilância neuromotora (ALMEIDA et al, 2013). Na criança 'D' 
Educação permanente do público-alvo para detecção precoce de alterações neuromotoras infantis

foi detectado atraso do desenvolvimento, história de prematuridade e, então, foi encaminhada para tratamento fisioterapêutico na Clínica de Fisioterapia da PUC-Campinas, onde a vaga foi reservada, mas a mãe não compareceu para preenchê-la com a criança. Na criança ' $E$ ' foi realizada a primeira avaliação; é uma criança prematura com história de bronquiolite viral e apresentou atraso em seu desenvolvimento neuromotor, necessitando de mais avaliações para sua confirmação (COUTINHO et al, 2015). A criança ' $F$ ' apresentou marcha independente e realizou praticamente todas as posturas esperadas para sua idade, não possuindo atraso neuromotor, e sim indício de quedas frequentes havendo a necessidade de realizar reavaliações periódicas mensais. Finalmente, a criança ' $G$ ' apresentou-se dentro da curva de percentil com um desenvolvimento adequado, porém, por ter nascido de 8 meses é aconselhável realizar um acompanhamento mensal. Observa-se no Quadro 2 que a criança ' $H$ ' não compareceu à avaliação, pois funcionários do CS relataram ser uma família complicada e com dificuldades diversas, então, continuaremos a insistência para que ocorra uma futura avaliação.

As crianças pré-termo apresentam baixos scores em suas avaliações motoras, onde a marcha independente é a principal aquisição que se apresenta com maior lentidão, sendo o $12^{\circ}$ mês a idade adequada para surgir esta aquisição. Souza e Magalhães (2012), assim como Borba et al (2013), mostraram que crianças nesta faixa etária apresentam maior dificuldade para o desenvolvimento neuromotor, uma vez que fatores ambientais e biológicos podem influenciar esses resultados, além da prematuridade (SOUZA e MAGALHÃES, 2012; BORBA et al, 2013).

Estima-se que no Brasil cerca de 11\% dos bebês nascem com prematuridade. Consequentemente, as morbidades relacionadas à prematuridade estão aumentando, como por exemplo, as sequelas neurológicas (BORBA et al, 2013). Apesar de ter sido avaliado um número pequeno de crianças na Unidade Básica de Saúde até o momento, pôde-se observar uma incidência alta de prematuros, representada por $50 \%$ das crianças avaliadas.

Ao contrário do estudo realizado por Borba et al (2013), no qual foi identificado um número maior de meninos nascidos pré-termo, em nosso estudo a maior parte de crianças nascidas pré-termo e com suspeita de atraso neuromotor foi do sexo feminino, sendo somente uma criança do sexo oposto. Logo, esta alta taxa de prematuridade e morbidade que atinge essas crianças são referentes ao impacto socioeconômico e cultural que acomete tal população.

De acordo com Garcia (2001), um estudo antigo realizado pela faculdade de Medicina da PUC-Campinas demonstrou que o impacto socioeconômico e cultural e as dificuldades políticas da região Noroeste de Campinas eram bastante notáveis. O autor observou também um grande número de habitantes e notou que a taxa de fertilidade era elevada; assim, mais 
Educação permanente do público-alvo para detecção precoce de alterações neuromotoras infantis

uma vez, em famílias numerosas constatou nível socioeconômico e cultural baixos, apresentando as seguintes características: grande parte da população não concluiu o ensino fundamental, alta taxa de desempregos, elevados números de analfabetos e uma renda familiar reduzida. Outro aspecto importante em seu estudo foi a falta de infraestrutura urbana com moradias com poucos cômodos e inacabados, esgoto a céu aberto, uma grande parte da população não procurava o CS para atendimento e, até aquela ocasião, as atividades de laser inexistiam.

A pesquisa realizada pelo mesmo autor em 2001, apesar de completar quinze anos, confirmou o que se pôde ver durante as atividades no CS Pq. Floresta, onde foram observadas e colhidas informações com sua equipe demonstrando que a população da região ainda apresenta as dificuldades mencionadas anteriormente. Contudo, o presente estudo comprovou que, na opinião da equipe de profissionais do CS, houve uma modificação para favorecer a qualidade de vida das pessoas, pois espaços destinados ao laser lhe foram ofertados, assim como melhoria da infraestrutura urbana e oportunidades de educação, mas ainda há uma grande dificuldade para diminuir as taxas de fertilização.

Contudo, o papel da universidade nas oficinas e nas vivências no CS é ouvir e compartilhar as dificuldades que os profissionais enfrentam, tendo em vista que os projetos de extensão procuram dar assistência e emancipação ao público-alvo de regiões que realmente necessitam de auxílio*.

Finalmente, todos os resultados apresentados não seriam possíveis se não houvesse a interação interdisciplinar com participação ativa de seus integrantes, assegurando bons resultados no âmbito social, econômico, político e cultural, prevenindo transtornos à saúde de bebês e crianças. (VELLOSO et al, 2015). A interdisciplinaridade promove comunicação de diferentes saberes, trocando conhecimentos de diversas áreas, realizada a partir da vivência dos profissionais envolvidos no processo. (ROQUETE et al, 2012).

\section{CONCLUSÃO}

Tendo em vista o que foi mencionado, a educação permanente dos profissionais do Centro de Saúde envolvidos no estudo possibilitou despertar nos genitores, ou responsáveis pelas crianças, o interesse e o conhecimento do desenvolvimento neuromotor infantil no contexto familiar, ambiental, escolar e social. Os profissionais desenvolveram também autonomia para realizar a educação dos pais desde a fase gestacional, que aprenderão como seus bebês se comportarão acerca das etapas neuromotoras durante seu desenvolvimento. 
Educação permanente do público-alvo para detecção precoce de alterações neuromotoras infantis

Dessa maneira, poderão elas mesmas reconhecer alterações ou atraso neuromotor infantil e sinalizarem suas preocupações para a equipe de saúde da atenção primária do município, que procederá ao encaminhamento das crianças comprometidas para avaliação e acompanhamento profissional especializado.

* Extraído de texto pessoal de PIRES, A.; CURY, V.E. Iniciativas e Desafios na elaboração de Projetos de Extensão em relação ao monitoramento e avaliação, recebido por correio eletrônico.

\section{REFERÊNCIAS}

AJAREM, J. S., et al. Camellia sinensis previne alterações neurocomportamentais induzidos por nicotina perinatais, lesão tecidual e estresse oxidativo em camundongos machos e fêmeas recém-nascidos. Oxid Med Cell Longev, v. 2017, 2017: 5985219, doi: 10.1155/2017/5985219. Disponível em: https://www.ncbi.nlm.nih.gov/pmc/articles/PMC5447281/. Acesso em 30 jun. 2017.

ALMEIDA, O. S. T., et al. Investigação sobre os Fatores de Risco da Prematuridade: uma Revisão Sistemática. Revista Brasileira de Ciências da Saúde, v. 17, n. 3, p. 301-308, 2013, ISSN 1415-2177. Disponível em: http://www.periodicos.ufpb.br/ojs/index.php/rbcs/article/view/13674/9814 Acessado em 26 out. 2016.

ANNE SHUMWAY-COOK. Controle motor - Teoria e aplicações práticas. Editora: Manole, $3^{\circ}$ edição, 2010.

BORBA, L.S.; SACCANI, R.; VALENTINI, N.C. Desenvolvimento neuromotor de crianças nascidas pré-termo e a termo avaliadas com a Escala Motora Infantil de Alberta. Temas sobre Desenvolvimento, 2013; 19(105):130-5. Disponível em: https://www.researchgate.net/publication/258699704 Desenvolvimento motor de criancas nascidas pre-termo e a termo avaliadas com a escala motora infantil de Alberta Acessado em 21 out. 2016.

BORELLA, P. M.; SACCHELLI, T. Os efeitos da prática de atividades motoras sobre a neuroplasticidade. Revista Neurociência. São Paulo, p. 161-169, 2008. Disponível em: http://www.revistaneurociencias.com.br/edicoes/2009/RN\%2017\%2002/14.pdf. Acessado em 03 nov. 2016.

BRASIL. MINISTÉRIO DA SAÚDE. AIDIPI - Atenção Integrada às Doenças Prevalentes na infância: curso de capacitação: introdução modulo 1 Ministério da Saúde, Organização Mundial da Saúde, Organização Pan-Americana da Saúde $-2^{\mathrm{a}}$ ed. Ver. - Brasília: Ministério da Saúde, 2002, ISBN 85-334-0605-3. Disponível em: http://bvsms.saude.gov.br/bvs/publicacoes/AIDPI modulo 1.pdf. Acessado em 14 out. 2016. 
Educação permanente do público-alvo para detecção precoce de alterações neuromotoras infantis

BROOKS-SCOT'T, SANDRA. Manual de mobilização para cuidados de crianças com distúrbios neurológicos. Editora: Manole, 2001.

CAMPOS, D.; SANTOS, D. C. C. Controle postural e motricidade apendicular nos primeiros anos de vida. Fisioterapia em Movimento, Curitiba, v. 18, n. 3, p.71-77, set. 2005. Disponível em: https://www.nescon.medicina.ufmg.br/biblioteca/imagem/0028.pdf. Acessado em 20 out. 2016.

COUTINHO, S. E. et al. Os múltiplos agentes associados à bronquiolite aguda e à gravidade da doença. BolCientPediatr. 2015;04(1):5-9. Disponível em:

http://www.sprs.com.br/sprs2013/bancoimg/150915221136bcped v4 n1 a3.pdf. Acessado em 28 set. 2016.

DORNELAS, F. L.; DUARTE, C. M. N.; MAGALHÂES, L. C. Atraso do desenvolvimento neuropsicomotor: mapa conceitual, definições, usos e limitações do termo. Revista Paulista de Pediatria. Associação de pediatria de São Paulo. Publicado por Elsevier Editora Ltda, p. 88-103, 2015. Disponível em:

http://www.scielo.br/pdf/rpp/v33n1/pt 0103-0582-rpp-33-01-00088.pdf. Acessado em: 20 set. 2016.

ESTADOS UNIDOS DA AMÉRICA. ORGANIZAÇÃO PAN-AMERICANA DA SAÚDE. Manual para vigilância do desenvolvimento infantil no contexto da AIDIPI. Washington, D.C.: OPAS, 2005, Série OPS/FCH/CA/05. 16 P, ISBN 927572606 X. Disponível em: https://www.nescon.medicina.ufmg.br/biblioteca/imagem/1711.pdf. Acessado em 14 out. 2016.

FLEHMIG.I. Texto e atlas do desenvolvimento normal e seus desvios no lactente: diagnóstico e tratamento precoce do nascimento até o $18^{\circ}$ mês. São Paulo: Editora Atheneu, 2002.

FONSECA, L. F.; LIMA, C. L. A. Paralisia Cerebral, 2º edição - Brasil: Medbook, 2008.

HALPERN, R. et al. Fatores de risco para suspeita de atraso no desenvolvimento neuropsicomotor aos 12 meses de vida. Jornal de Pediatria. Porto Alegre, v. 76, n. 6, 2000. Disponível em: https://www.sap.org.ar/docs/publicaciones/archivosarg/2002/61.pdf Acessado em 12 set. 2016.

LUCAS, B. R. et al. Intervenções para melhorar o desempenho motor grosso em crianças com transtornos do neurodesenvolvimento: uma meta-análise. BMC Pediatr, v.16; 2016 Nov, 29. doi: 10.1186/s12887-016-0731-6. Disponível em: https://www.ncbi.nlm.nih.gov/pmc/articles/PMC5129231/ Acessado em: 28 jun. 2017.

MAIA, J. M. D. \& WILLIAMS, L. C. A. Fatores de risco e fatores de proteção ao desenvolvimento infantil: uma revisão da área. Temas em psicologia, 13 (2): 91-103,2005, ISSN 1413-389X. Disponível em: http://www.laprev.ufscar.br/documentos/arquivos/artigos/2005-maia-e-williams.pdf. Acessado em 17 set. 2016. 
Educação permanente do público-alvo para detecção precoce de alterações neuromotoras infantis

MELO, R. T. Escalas de Avaliação do Desenvolvimento e Habilidades Motoras: AIMS, PEDI, GMFM e GMFCS. Fisioterapia em movimento. Capitulo 2, p. 25-37, 2011, ISBN 978-85-64619-01-2. Disponível em: http://omnipax.com.br/livros/2011/FNP/FNP_ cap2.pdf. Acessado em 20 out. 2016.

KANG, L. et al. Barreiras ambientais à participação de crianças pré-escolares com e sem deficiência física. Int J Environ Res Public Health. v, 14(5); 2017 May; 14(5): 518. Disponível em: https://www.ncbi.nlm.nih.gov/pmc/articles/PMC5451969/Acessado em 03 jun. 2017.

MORAIS, S. L. R.; CARVALHO, M. A.; MAGALHÃES C. L. O contexto ambiental e o desenvolvimento na primeira infância: estudos brasileiros. J. Phys. Educ. v, 27, e2714, 2016. Disponível em:

http://www.periodicos.uem.br/ojs/index.php/RevEducFis/article/view/25672/16874

Acessado em 14 out. 2016.

PIPER, M. C.; DARRAH, J. Motor assessment of the developing infant Philadelphia: W. B. Saunders Company, 1994.

ROQUETE, F. F. et al. Multidisciplinaridade, interdisciplinaridade e transdisciplinaridade: em busca de diálogo entre saberes no campo da saúde coletiva. Revisa de enfermagem do centro oeste mineiro, p. 463- 474, 2012. Disponível em:

http://www.seer.ufsj.edu.br/index.php/recom/article/viewFile/245/361. Acessado em 26 set. 2016.

SACCANI, R. \& VALENTINI, N. C. Reference curves for the Brazilian Alberta Infant Motor Scale: percentiles for clinical description and follow-up over time. Jornal de Pediatria - Vol. 88, $\mathrm{N}^{\circ}$ 1, 2012. Disponível em:

http://www.scielo.br/pdf/jped/v88n1/a07v88n01.pdf Acessado em 01 jul. 2016.

SEVERINO, A. J. Metodologia do trabalho científico. 24 Ed. - São Paulo: Cortez, 2016.

SPESSATO, C. B. et al. Educação infantil e intervenção motora: um olhar a partir da teoria bioecológica de Brnfenbrenner. Movimento. Porto Alegre, v. 15, n. 04, p. 147-173, 2009. Disponível em: https://seer.ufrgs.br/Movimento/article/view/5617/6951 Acessado em 13 set. 2016.

SOUZA, S. E.; MAGALHÂES, C. L. Desenvolvimento neuromotor e funcional em crianças nascidas pré-termo e a termo: influências de fatores de risco biológico e ambiental. P.462-470, 2012. Disponível em: http://www.scielo.br/pdf/rpp/v30n4/02.pdf. Acessado em 17 set. 2016.

TECKLIN, J. S. Fisioterapia Pediátrica. $3^{a}$ ed. - Porto Alegre: Artmed, 2002.

VELLOSO, P. M. et al. Interdisciplinaridade e formação na área da saúde coletiva. p. 257- 271, 2015. Disponível em: http://www.scielo.br/pdf/tes/v14n1/1981-7746-tes-14-010257.pdf. Acessado em 20 set. 2016.

Recebido em: 25/10/2017

Aceito em: 22/11/2018 